\title{
A CRIMINALIDADE NO ESTADO DE PERNAMBUCO: UMA ANÁLISE ESPACIAL DOS DETERMINANTES DAS OCORRÊNCIAS DE HOMICÍDIOS E ROUBOS
}

Álvaro Robério de Souza Sá1.

1 - Bacharelado em Ciências Econômicas pela Universidade Federal Rural de Pernambuco (UFRPE) e Historiador pelo Centro Universitário de Maringá (Unicesumar). Mestrando em Economia Aplicada pela Universidade Federal de Pernambuco (UFPE/CAA). Email: alvaro.roberiosa@gmail.com

\section{Resumo}

Pernambuco entrou em uma crescente dos Crimes Violentos Letais Intencionais (CVLI) e Crimes Violentos contra o Patrimônio (CVP) recentemente. Diante desse contexto, essa pesquisa teve como finalidade identificar os condicionantes econômicos, sociais e geográficos da criminalidade no território pernambucano em 2016 . Para tanto, utilizou-se técnicas de Análise Exploratória de Dados Espaciais (AEDE) e modelos com componentes espaciais. Entre os resultados, constatou-se que existe autocorrelação espacial positiva dos casos de homicídio e roubo no estado. Foram ainda identificados clusters de criminalidade na Região Metropolitana do Recife (RMR), Agreste e Sertão. Ademais, verificou-se através dos modelos espaciais estimados que existem efeitos de transbordamento e repercussão da criminalidade no estado.

Palavras-chave: Criminalidade; Análise Espacial; Pernambuco.

\begin{abstract}
Pernambuco has recently entered into an increasing number of Intentional Lethal Crimes (CVLI) and Violent Crimes Against Heritage (CVP). Given this context, this research aimed to identify the economic, social and geographic conditions of crime in the Pernambuco territory in 2016. For this purpose, techniques of Exploratory Analysis of Spatial Data (AEDE) and models with spatial components were used. Among the results, it was found that there is positive spatial autocorrelation of homicide and theft cases in the state. Crime clusters were also identified in the Metropolitan Region of Recife (RMR), Agreste and Sertão. In addition, it was verified through the estimated spatial models that there are spillover effects and repercussions of crime in the state.
\end{abstract}

Keywords: Criminality; Spatial Analysis; Pernambuco. 


\section{INTRODUÇÃO}

A criminalidade tem chamado a atenção da população, agentes governamentais e de profissionais da imprensa nos últimos anos, em virtude dos seus índices alarmantes e de suas consequências sobre o bem-estar da sociedade e atividade econômica.

O Estado de Pernambuco se insere nesse contexto de aumento da violência, uma vez que estatísticas recentes evidenciam um processo de exaustação do Pacto Pela Vida (PPV). Esse programa de segurança pública foi criado durante o Governo de Eduardo Campos, com a finalidade de reduzir e controlar a criminalidade. Entre 2007 e 2013, essa política pública reduziu as ocorrências de homicídios em 40\%. Contudo, entre 2014 e 2017 houve um descuido com a segurança pública do estado e a violência aumentou em 58\% (RATTON et al., 2014; CERQUEIRA, 2018).

A explosão da criminalidade no território pernambucano também ocorreu em um cenário de retração econômica, arrocho fiscal e elevado nível de desemprego. A respeito deste último aspecto, o estado registrou uma redução de 70,8 mil postos de empregos formais entre 2016 e 2018, enquanto a economia nacional teve um tombo de 1,4 milhão (MINISTÉRIO DO TRABALHO, 2019).

O aumento da violência tem provocado uma forte reflexão nos formuladores de políticas públicas do estado, em decorrência dos seus efeitos diretos e indiretos sobre os diversos eixos da economia. Entre 2014 e 2016, a economia estadual elevou em 30,4\% as ocorrências de homicídios, com média de 3,9 mil mortes por ano, segundo dados da Secretaria de Defesa Social do Estado (2019). Nesse período, Pernambuco foi o quinto estado com maior taxa média de homicídios por 100 mil/habitantes na região Nordeste e oitavo no panorama nacional.

É importante destacar que a criminalidade se encontra relacionada com um amplo conjunto de fatores, tais como: ciclos econômicos, desemprego, desorganização urbana, desigualdade de renda, obras públicas, concentração da pobreza, ineficiência da política de segurança pública e mecanismos de justiça. Os aspectos citados tem corroborado para a alavancagem da violência no território brasileiro e pernambucano, este último registrou a marca histórica de 5,4 mil homicídios em 2017 (CARRERA-FERNANDEZ, 2003).

Em relação às despesas com segurança pública, Pernambuco teve um aumento real de $66 \%$ entre 2007 e 2011 , época em que ocorreu uma forte redução da violência no território estadual, principalmente em virtude da implantação do Pacto Pela Vida (PPV). Entre 2014 e 2015, os altos índices de criminalidade retornaram e o estado registrou uma redução real no dispêndio com segurança pública de $9 \%$. De 2015 a 2016 a despesa diminuiu em apenas 2\%. Na tentativa de reverter o cenário de violência, no ano seguinte, o governo optou por expandir o gasto público com segurança em 8\% (IPEADATA, 2019).

Diante desse contexto, o maior desafio do governo pernambucano na atualidade é formular e implementar uma política pública que contemple a redução da violência e promova a mitigação dos seus determinantes. Por essa razão, os estudos nessa área tem se multiplicado, com a finalidade de mensurar e explicar quais fatores são condicionantes da criminalidade. As pesquisas nesse campo visam fornecer informações para o aparelho estatal e traçar novas estratégias para a segurança pública, em razão de sua relevância para o progresso socioeconômico (FAJNZYLBER; ARAUJO JR., 2001). 
Considerando as contribuições teóricas de Becker (1968), Ehrlich (1973), Block e Heineke (1975), Leung (1995) e Zhang (1997) sobre economia do crime, essa pesquisa tem como objetivo analisar os condicionantes da criminalidade no contexto espacial do Estado de Pernambuco. Especificamente, pretende-se avaliar quais fatores influenciam a violência no estado e se existe um padrão de organização espacial. Para atingir essa finalidade, foram analisadas variáveis econômicas, sociais e geográficas que afetam os Crimes Violentos Letais Intencionais (CVLI) e Crimes Violentos contra o Patrimônio (CVP), obtidos na Secretaria de Defesa Social para 2016.

Ademais, este trabalho contribui para o processo de formulação de políticas públicas de combate à violência no Estado, a partir da identificação dos fatores que corroboram para o aumento desse fenômeno social e que tanto afetam a economia e a população.

Além dessa introdução e das considerações finais, este artigo apresenta na seção seguinte a fundamentação teórica sobre economia do crime e uma revisão dos estudos realizados nesta área para o Brasil. Posteriormente, discorre sobre a metodologia usada e os resultados obtidos na pesquisa.

\section{FUNDAMENTAÇÃO TEÓRICA}

\subsection{Teoria Econômica do Crime}

Os estudos sobre economia do crime tem seu marco inicial com o trabalho seminal do economista Gary Becker (1968) intitulado de "Crime and Punishment: An Economic Approach", que apresenta uma abordagem fundamental para análise dos determinantes da violência. Este teórico formulou um modelo para explicar as causas da criminalidade, através da avaliação das escolhas racionais dos agentes econômicos, em outras palavras, como os indivíduos optam pela prática da atividade ilegal.

Nessa teoria, o ato criminoso é resultado da decisão do agente racional em torno de um conjunto de oportunidades que podem ser lícitas ou ilícitas. Dadas as oportunidades disponíveis, a escolha do indivíduo em praticar ou não um crime se encontra associada ao processo de maximização da utilidade esperada. Assim, o indivíduo escolhe aumentar seu bem-estar através da ação criminosa quando considerar baixas as chances de punição e custo do delito (CERQUEIRA e LOBÃO, 2004).

A avaliação de custo e benefício decorre do confronto entre o salário que o agente pode alcançar no mercado formal (lícito) em relação ao informal (ilícito). Portanto, uma vez que a utilidade esperada do indivíduo no mercado lícito não exceda a do mercado ilícito, este pode decidir alocar seu tempo e demais recursos na atividade criminosa, com a finalidade de aumentar o seu nível de bem-estar (BECKER, 1968).

Segundo Becker (1968) os indivíduos escolhem o mercado legal influenciados por fatores positivos, como salário e renda, enquanto a decisão de entrar no mercado ilegal é impulsionada por condicionantes negativos, como aparato policial e judiciário, uma vez que estes são responsáveis pelo ato de punição ao crime. Os postulados apresentados podem ser resumidos através da seguinte equação:

$$
E U_{j}=p_{j} U_{j}\left(\gamma_{j}-f_{j}\right)+\left(1-p_{j}\right) U_{j}\left(\gamma_{j}\right)
$$


Em que $E U$ representa a função utilidade esperada do indivíduo, $j$ o indivíduo, $p_{j}$ probabilidade do indivíduo ser preso e punido, $\gamma_{j}$ o rendimento monetário do crime e $f_{j}$ corresponde ao custo monetário de punição (no caso de prisão). Assim, variações em $p_{j}$ ou $f_{i}$ podem alterar o nível de bem-estar do agente racional pela prática de atividade ilícita. Nesses termos, o indivíduo somente optará pelo ato criminoso nos casos em que a taxa de retorno esperada pelo ato ilegal supere a do ato legal, a depender das variações probabilísticas de prisão, punição e custo do delito.

Nesse contexto, Becker (1968) ainda estudou a quantidade ótima de recursos e punições que minimizam os custos sociais do crime. Ele parte do pressuposto de que a legislação em vigor não é obedecida de modo integral pelos agentes econômicos e que as despesas do setor público e privado não são suficientes para prevenção da criminalidade e apreensão de criminosos. Deste modo, considera que as sanções legais são normalmente inadequadas e que tais ações provocam perdas sociais.

Nessa perspectiva, Becker (1968) ainda discorre sobre a eficiência da aplicação de multas para compensar os efeitos da violência sobre as famílias das vítimas. Ele retrata que seria coerente compensar monetariamente as famílias atingidas pela violência. Nesse sentido, cabe aqui diferenciar prisão de multa, uma vez que a primeira se associa ao tempo de reclusão do agente, ao passo que a segunda aos valores pecuniários. Nesses termos, as punições monetárias reduzem o custo social da violência, tendo em vista que as vítimas podem ser indenizadas. Ademais, o teórico considera essa ação como uma maneira eficaz de equiparação do setor público aos afetados pela criminalidade.

Seguindo essa linha teórica, Isaac Ehrlich (1973) propõe uma análise econômica do crime fundamentada na escolha ocupacional dos indivíduos frente aos incentivos de mercado, ou seja, das oportunidades dadas as preferências. No texto "Participation in illegitimate activities: a theoretical and empirical investigation", o teórico investiga os efeitos da distribuição de renda sobre os crimes contra o patrimônio.

O modelo econômico desenvolvido por Ehrlich (1973) enfatiza a participação dos agentes em atividades criminosas e corrobora para a distinção entre alocação de tempo individual entre trabalho legal e ilegal. O trabalho do autor se diferencia do de Becker, uma vez que apresenta uma função de oferta de crimes incluindo a variável rendimento da atividade lícita e ilícita, assim como a possibilidade de desemprego. A função pode ser expressa da seguinte forma:

$$
O=o(p, f, w i, w l, u, \pi)
$$

Em que $p$ probabilidade do criminoso ser preso e condenado, $f$ penalidade imposta ao criminoso, $w i$ rendimentos provenientes de atividades ilegais, $w l$ rendimentos provenientes de atividades legais, $u$ desemprego e $\pi$ outras variáveis que podem influenciar na escolha individual (educação, renda, moradia, entre outras).

Nesse contexto, o comportamento do agente racional se apresenta relacionado aos custos de oportunidade de cometimento do crime, nível de renda, empregabilidade e chances de prisão e punição, ou seja, de eficiência do serviço policial e judicial. Portanto, o crescimento das desigualdades socioeconômicas eleva a criminalidade, sobretudo dos crimes contra a propriedade ou patrimônio (EHRLICH, 1973). 
A curva de demanda por crime apresenta ainda um nível de tolerância de atos ilícitos que a sociedade está disposta a aceitar, uma vez que um nível nulo de violência exigiria um elevado custo com segurança pública, contudo, o bem-estar social obtido não justificaria tamanho dispêndio. Portanto, a função demanda agregada do crime existe pelo fato do aparelho estatal não dispender ou não dispor de recursos suficientes para eliminar totalmente a criminalidade do meio social (MARIANO, 2010).

De acordo com Cerqueira e Lobão (2004) essa teoria estabelece uma relação entre os crimes contra a propriedade e as oportunidades oferecidas pelas vítimas potenciais. Para proceder com essa análise, utiliza-se como determinante o nível de renda mediano e a porcentagem de famílias que recebem até o primeiro quartil da renda global. Por essa razão, existe uma associação direta entre desigualdade econômica e criminalidade.

Nesse contexto, Block e Heineke (1975) apresentam uma crítica aos estudos de Becker (1968) e Ehrlich (1973), elencando que as atividades ilegais não estão associadas apenas a distribuição de renda, mas também a outros aspectos que levam o indivíduo a tomar essa decisão ou não, tais como: princípios éticos e morais e fatores psicológicos.

Nessa perspectiva, o problema de escolha do agente racional não se limita apenas a um processo decisório de trabalho como enfatiza Becker (1968), pois se restringiria a uma interpretação de custo e benefício estritamente monetária. Para proceder com a análise, Block e Heineke (1975) consideram que o indivíduo pode distribuir seu tempo em duas atividades geradoras de riqueza, uma legal e outra ilegal . A utilidade do indivíduo é alcançada através de uma função do tempo alocado na geração de riqueza, descrita da seguinte forma:

$$
U=U(L, T, W)
$$

(3)

Em que $U$ representa a utilidade do agente e $W$ a riqueza, enquanto que $U_{W}>0, U_{L}<0$ e $U_{T}<0$. Portanto, ao incluir os $\operatorname{argumentos} L$ e $T$ explicitamente em $U$, Block e Heineke (1975) passam a investigar os aspectos éticos e morais que podem restringir ou influenciar na decisão individual entre atividade formal e informal.

Block e Heineke (1975) ainda discorrem que as penalidades pela atividade ilegal não se restringem apenas as multas, uma vez que existem efeitos psicológicos que recaem sobre a escolha individual. O comportamento individual não se associa apenas aos riscos e retornos relativos, mas também aos efeitos psíquicos de ocupações alternativas. Assim, o problema da oferta agregada de crime apresentada anteriormente deveria ser formulada em termos de preferências multifatoriais, pois incluiria aspectos éticos, morais e mentais do indivíduo e não apenas a renda (CERQUEIRA e LOBÃO, 2004).

Nessa linha, Zhang (1997) apresenta uma contribuição a teoria econômica do crime, através de um modelo que enfatiza a relevância dos programas de bem-estar social como redutores da violência. Os programas sociais fornecem renda aos indivíduos que se encontram à margem da sociedade - população propensa à atividade criminosa —, afetando a função alocativa do tempo individual em atividades ilegais e contribuindo para redução da criminalidade.

Outra teoria que emergiu nesse contexto foi a do histórico criminal do indivíduo. Segundo essa corrente, uma vez que o agente ingresse no mercado ilegal suas chances de retorno ao mercado legal são mínimas. O retorno ao mercado formal se torna de difícil acesso, em razão da trajetória criminal anterior e do estigma social da população ao ex-criminoso (CERQUEIRA e LOBÃO, 2004). 
Além disso, o passado criminoso do indivíduo reduz os retornos futuros esperados no mercado formal, uma vez que existe preconceito social, depreciação do capital humano e ausência de investimento para qualificação, requalificação e até mesmo ressocialização do ex-criminoso (LEUNG, 1995).

Diante do exposto, conclui-se que a teoria econômica do crime tem evoluído ao longo do tempo sempre buscando novos determinantes para esse fenômeno, assim como aperfeiçoando esse eixo das ciências sociais aplicadas.

\subsection{Estudo espacial da criminalidade na literatura econômica brasileira}

Nas últimas décadas, os estudiosos sobre economia do crime tem utilizado com maior frequência o ferramental estatístico da área de econometria espacial para mensurar e identificar os determinantes da violência municipal, estadual e regional.

Os estudos buscam avaliar como variáveis socioeconômicas e o espaço geográfico explicam a concentração e distribuição da violência na economia, além dos seus efeitos de transbordamento e repercussão entre as economias no contexto espacial.

Diante desse contexto, Moreira e Fochezatto (2018) analisam os condicionantes da criminalidade agregada no território do Estado da Bahia para o ano de 2014. Entre os resultados, constatou-se que o aumento da violência está associado a maior concentração populacional e produção agregada per capita. Por outro lado, educação e emprego formal não foram estatisticamente significativos para explicar a evolução da violência no estado.

Estudando a criminalidade da Região Metropolitana de Porto Alegre, Carrets et al. (2018) verificam que há maior dinâmica geográfica das ocorrências de homicídios na região litoral ao longo do tempo, enquanto que crimes contra o patrimônio exibem menor grau de associação espacial.

Nessa linha, Olini et al. (2019) demonstram que no Estado do Mato Grosso existe uma relação espacial entre as taxas de homicídios e a desigualdade de renda, entre 2000 e 2010. Para isso, os autores utilizaram como determinante o coeficiente de Gini.

Ao analisar os fatores que exercem efeito sobre as taxas de homicídios no território do Estado do Paraná, Bondezan et al. (2018) evidenciam que a distribuição da violência não ocorre de forma aleatória no espaço geográfico e que os casos de assassinato se encontram concentrados na Região Metropolitana de Curitiba. A avaliação dos fatores determinantes da criminalidade foi processada através de modelos de defasagem do termo de erro (SEM) e Durbin espacial do termo de erro (SDEM), que identificaram que variáveis como densidade demográfica, Gini, desemprego, atraso escolar e proporção de jovens do sexo masculino estão diretamente associadas a variável de interesse. No que tange ao efeito espacial, constatou-se que existe transbordamento da violência entre as economias paranaenses.

Analisando a importância das características socioeconômicas, institucionais e de localização na determinação das taxas de homicídios dos estados brasileiros, Uchôa e Menezes (2012) identificaram que efeitos diretos, indiretos e totais aumentam a violência em um estado com reflexo positivo (negativo) na dos seus vizinhos. Ademais, concluiu-se que desigualdade de renda, desemprego, impunidade e densidade são condicionantes da violência no território brasileiro. 
Discorrendo sobre os aspectos e padrões espaciais determinantes para explicar a violência no território pernambucano, Oliveira Júnior (2013) observou a dinâmica das ocorrências de homicídios por faixa etária e sexo das vítimas entre 1981 e 2010 . Entre os resultados, concluiu-se que ocorreu aumento no número de homicídios na faixa etária de 20 a 29 anos de homens e mulheres em todo o período, porém, na década de 2000 somente as mulheres de 20 a 29 anos não exibiram tendência de decrescimento. Considerando a sazonalidade, inferiu-se que ocorreu um aumento dos homicídios nos meses de dezembro e janeiro, com exceção para mulheres de 30 a 59 anos.

No que tange a composição de clusters de criminalidade, a saída dos resultados indicaram que existem dois aglomerados espaciais no Pernambuco, um conhecido como Polígono da Maconha e outro na Região Metropolitana do Recife (RMR) até a década de 1990. Por fim, o estudo sugere que além dos determinantes sociais, o tráfico de drogas pode estar fortemente ligado às ocorrências de homicídios e que os meses de dezembro e janeiro são os de maiores riscos de crimes letais no estado (OLIVEIRA JÚNIOR, 2013).

O Nordeste tratado nos manuais de geografia como a rugosidade econômica do país tem sua violência determinada pelos fatores socioeconômicos e aspectos de formação histórica, econômica, social e política. Considerando esses aspectos, Plassa et al. (2017) identificaram os condicionantes das taxas de homicídios dessa região para o ano de 2014. O cômputo do estudo indicou que a desigualdade de renda é o condicionante que exerce o maior impacto nas taxas de homicídios dos municípios nordestinos e que existe um efeito espacial de spillovers da violência no território.

Portanto, pode-se concluir que os estudos sobre os determinantes da criminalidade em uma abordagem econométrica espacial tem sido amplamente usado por pesquisadores do país, com a finalidade de contribuir na formulação de políticas de segurança pública e na redução da violência.

\section{METODOLOGIA}

Para identificar os determinantes da criminalidade no território pernambucano no ano de 2016, este estudo utilizou ferramentas de econometria espacial. A rigor, fez-se uso da Análise Exploratória de Dados Espaciais (AEDE), que corresponde a um conjunto de técnicas estatísticas para identificação de padrões espaciais nos dados. Posteriormente, estimou-se modelos econométricos empregando componentes espaciais.

Os modelos estimados neste trabalho utilizam todas as variáveis em logaritmo natural e tem como variáveis de interesse: ocorrências de homicídios (CVLI) e roubos (CVP). Na seção seguinte, apresenta-se a base de dados, a descrição das variáveis e os procedimentos metodológicos empregados de acordo com Anselin (1999), Almeida (2012), Bondezan et al. (2018), Moreira e Fochezatto (2018) e Plassa e Parré (2019).

\subsection{Apresentação das variáveis e fonte dos dados}

A base de dados desse estudo é formada por 185 municípios do Pernambuco. Os dados foram extraídos de órgãos oficiais, tais como: Instituto Brasileiro de Geografia e Estatística (IBGE), Secretaria de Defesa Social do Pernambuco (SDS/PE), Banco de Dados do Estado (BDE/PE) e Instituto Nacional de Estudos e Pesquisas Educacionais Anísio Teixeira (INEP). 
As variáveis dependentes correspondem aos Crimes Violentos Letais Intencionais (CVLI) e Crimes Violentos contra o Patrimônio (CVP) dos municípios pernambucanos para 2016, respectivamente homicídios e roubos. As variáveis escolhidas refletem os níveis de violência no estado, uma vez que a primeira expressa os crimes mais graves ocorridos na sociedade, ao passo que a segunda os crimes de motivação econômica e financeira (SANTOS, 2007; MARIANO, 2010).

As variáveis explicativas foram selecionadas com base no referencial teórico e revisão da literatura sobre economia do crime. Foram selecionadas as seguintes variáveis: densidade demográfica, renda, escolaridade, atraso escolar, divórcio, tráfico de drogas e furtos.

Nesse contexto, a densidade demográfica verifica o efeito urbano e aglomerativo sobre os casos de homicídio e roubo. Ela também reflete a menor probabilidade de prisão e reconhecimento do criminoso na vida urbana e, portanto, se encontra diretamente ligada ao aumento da violência (GLAESER e SACERDOTE, 1999).

O divórcio foi utilizado como proxy para captar o efeito da desorganização no núcleo familiar, pois também corrobora para os indivíduos entrarem no mundo do crime (ARAÚJO JÚNIOR e FAJNZYLBER, 2000).

A renda apresenta relação com o aumento da violência, porém, na literatura econômica tem exibido efeito ambíguo. Assim, regiões onde o estoque de riqueza das vítimas é mais elevado existe uma grande propensão de crimes, sobretudo contra o patrimônio (ARAÚJO JÚNIOR e FAJNZYLBER, 2000). Além disso, existe um efeito positivo que decorre dos maiores retornos da atividade criminosa por parte dos indivíduos que optam pela atuação no mercado ilegal. Portanto, quanto maior o nível de renda da população maior será o retorno esperado na atividade ilegal (MARIANO, 2010).

O efeito da educação sobre as ocorrências de homicídios foi captado através da taxa de atraso escolar, mensurada a partir da distorção idade-série dos alunos do ensino fundamental. Foi utilizada também como proxy para a educação o número de pessoas com 25 anos ou mais de idade com ensino médio completo e superior incompleto. Espera-se que o aumento da escolaridade exiba relação inversa com a violência, uma vez que há um aumento no custo de oportunidade do indivíduo com instrução para ingressar no mercado ilegal (BECKER, 1968).

Segundo Oliveira (2008) o efeito da escolaridade sobre a criminalidade pode ser impreciso, tendo em vista que as instituições de ensino podem não cumprir seus papéis na construção da cultura do trabalho e da paz entre os jovens. Além disso, indivíduos com pouca qualificação profissional ocupam posições de pouco privilégio no mercado de trabalho, ou seja, recebem baixa remuneração e se tornam alvos fáceis para o mundo do crime.

Por fim, utilizou-se ainda tráfico de drogas e furtos como variáveis explicativas para as ocorrências de homicídios e roubos, pois se encontram associadas a cobrança de dívidas de mercadorias ilegais e conflitos territoriais (MARIANO, 2010; ROCHA, 2012).

O Quadro 1 apresenta a definição e estatística descritiva das variáveis usadas neste estudo com base na literatura econômica revisada. 
Quadro 1 - Definição e estatística descritiva das variáveis utilizadas.

\begin{tabular}{|c|c|c|c|c|}
\hline Variável & Definição & Fonte & Média & $\begin{array}{l}\text { Desvio } \\
\text { Padrão }\end{array}$ \\
\hline CVLI & Número de vítimas de crimes violentos letais intencionais. & $\mathrm{SDS} / \mathrm{PE}$ & 24.21 & 60.77 \\
\hline CVP & Número de crimes violentos contra o patrimônio. & $\mathrm{SDS} / \mathrm{PE}$ & 615.67 & 3263.00 \\
\hline $\begin{array}{l}\text { Tráfico de } \\
\text { Drogas }\end{array}$ & Número de ocorrências relacionadas ao tráfico de drogas. & $\mathrm{SDS} / \mathrm{PE}$ & 20.89 & 104.08 \\
\hline Furto & Número de ocorrências relacionadas a furtos. & $\mathrm{SDS} / \mathrm{PE}$ & 389.49 & 1930.53 \\
\hline Renda & Remuneração média dos trabalhadores. & RAIS & 20789.9 & 157298.3 \\
\hline Divórcio & $\begin{array}{l}\text { Número de divórcios consensuais concedidos em } 1^{\mathrm{a}} \text { instância } \\
\text { ou por escritura. }\end{array}$ & IBGE & 58.62 & 142.07 \\
\hline Educação & $\begin{array}{l}\text { Pessoas de } 25 \text { anos ou mais de idade com ensino médio } \\
\text { completo e superior incompleto / população estimada } \\
\text { (escolaridade). }\end{array}$ & IBGE & 5991.7 & 24395.37 \\
\hline $\begin{array}{l}\text { Atraso } \\
\text { Escolar }\end{array}$ & $\begin{array}{c}\text { Proporção de alunos, em cada série/ano, do ensino } \\
\text { fundamental ( } 1^{\circ} \text { ao } 5^{\circ} \text { ano) com idade superior ao } \\
\text { recomendado (6 a } 10 \text { anos). }\end{array}$ & INEP & 17.39 & 4.58 \\
\hline $\begin{array}{l}\text { Densidade } \\
\text { Demográfica }\end{array}$ & $\begin{array}{l}\text { Relação entre a população e a área geográfica municipal } \\
\qquad\left(\mathrm{Km}^{2}\right) .\end{array}$ & IBGE & 262.89 & 947.87 \\
\hline
\end{tabular}

Fonte: Elaboração própria (2019).

O Quadro 2 apresenta os efeitos esperados das variáveis explicativas sobre os casos de homicídio (CVLI) e roubo (CVP), conforme a teoria exposta.

Quadro 2 - Efeito esperado das variáveis explicativas.

\begin{tabular}{|c|c|c|}
\hline Variáveis Explicativas & Efeito em CVLI & Efeito em CVP \\
\hline Renda & Positivo ou Negativo & Positivo ou Negativo \\
\hline Densidade Demográfica & Positivo & Positivo \\
\hline Atraso Escolar & Positivo & - \\
\hline Divórcio & Positivo & Positivo \\
\hline Tráfico de Drogas & Positivo & Positivo \\
\hline Furto & - & Positivo \\
\hline Educação & - & Negativo ou Positivo \\
\hline
\end{tabular}

Fonte: Elaboração própria (2019).

\subsection{Análise Exploratória de Dados Espaciais (AEDE)}

A Análise Exploratória de Dados Espaciais (AEDE) corresponde a um conjunto de técnicas de análise estatística que tem como finalidade descrever e apresentar o tipo de distribuição ou regime espacial presente nos dados (ALMEIDA, 2012; ANSELIN, 1999). 
Segundo Plassa e Parré (2019), para realizar essa análise faz-se necessário escolher uma matriz de ponderação espacial ( $W$ ), que serve para captar os efeitos de contiguidade e vizinhança nos dados. Este trabalho testa as convenções de pesos espaciais Rainha e Torre, que são as mais difundidas na literatura sobre econometria espacial.

Posteriormente, observa-se como as variáveis de interesse estão distribuídas no espaço geográfico, se aleatoriamente ou se autocorrelacionadas. Para isto, analisa-se o grau de dependência espacial através do Índice de Moran, ferramenta estatística, que além de verificar a presença de autocorrelação também identifica padrões de dependência espacial nos dados (MOREIRA e FOCHEZATTO, 2018).

O \$ \$I de Moran é um coeficiente de autocorrelação espacial que usa medida de autocovariância na forma de produto cruzado para sumarização da distribuição espacial dos dados, conforme Plassa e Parré (2019) e Santos e Raia Júnior (2006). Essa estatística pode ser expressa da seguinte forma:

$$
I=\frac{n \sum \sum_{i} w_{i j} z_{i} z_{j}}{S_{0} \sum_{i=1}^{n} z_{i}^{2}}
$$

(4)

Em que $n$ representa o número de unidades espaciais, $z$ os valores da variável de interesse padronizada, $w_{i j}$ os valores médios da variável de interesse padronizada dos vizinhos definida segundo uma matriz de ponderação espacial $w$ e $S_{0}$ significa a soma de todos os elementos das matrizes espaciais $w$ (ALMEIDA, 2012).

Nesse contexto, o valor esperado do $I$ de Moran sob hipótese nula de ausência de autocorrelação espacial é dado por [ $\left.\frac{1}{(n-1)}\right]$. Segundo Almeida (2012) se o valor mensurado for maior (menor) que o valor esperado então há evidência de autocorrelação espacial positiva (negativa), ou seja, a variável dependente exibe valor alto (baixo) em uma localidade e o seu vizinho também apresenta valor alto (baixo) desta mesma variável.

Devido ao $I$ de Moran global não captar eventuais padrões espaciais significativos de associação, se usa um indicador de concentração espacial para análise local (PLASSA e PARRÉ, 2019; BONDEZAN et al., 2018). Diante disso, decompõe-se o indicador global de autocorrelação espacial para o contexto local de cada observação do estudo, através de um divisão em quatro categorias (AA, $\mathrm{BB}, \mathrm{AB}$ e $\mathrm{BA}$ ). Nesse sentido, Alto-Alto (AA) refere-se a uma região com atributo alto em relação à média e seu vizinho também é alto, enquanto que Baixo-Baixo $(\mathrm{BB})$ indica que a região com atributo baixo em relação à média e seu vizinho também é baixo, e assim por diante (ANSELIN, 1999).

Segundo Plassa e Parré (2019) e Bondezan et al. (2018) os resultados do I de Moran local podem ser exibidos de forma eficiente e robusta através do mapa de clusters LISA — Local Indicator of Spatial Association —. Para isto, no entanto, deverá ser capaz de atender os seguintes critérios: capacidade das observações indicarem clusters espaciais estatisticamente significativos e que a propriedade do somatório dos indicadores locais para todas as regiões sejam proporcionais ao indicador de autocorrelação espacial global correspondente. 


\subsection{Modelos econométricos espaciais}

Após verificar a existência de dependência espacial, utiliza-se modelos espaciais para avaliar os determinantes das ocorrências de homicídios (CVLI) e roubos (CVP) para o território pernambucano.

Neste estudo, foram estimados os modelos espaciais de defasagem SAR e SEM. No primeiro, a defasagem ocorre na variável de interesse da regressão, enquanto que no segundo a defasagem incide no termo de erro (BONDEZAN et al., 2018). Segundo Almeida (2012) inicialmente estima-se um modelo de regressão linear clássico usando o método dos Mínimos Quadrados Ordinários (MQO):

$$
Y=\alpha+X \beta+\varepsilon
$$

(5)

Em $y$ corresponde a um vetor $n \times 1$ de observações sobre a variável dependente, enquanto $x$ é uma matriz $n \times K$ de observações das variáveis explicativas (mais a constante) com um vetor associado $k \times 1$ de coeficientes de regressão $\beta$ e $\epsilon$ é um vetor $n \times 1$ do distúrbio aleatório, com média zero e variância constante.

Em seguida, testa-se a hipótese de ausência de autocorrelação espacial pelo $I$ de Moran. Após realizar esse teste, caso exista autocorrelação espacial, faz-se necessário encontrar o modelo que ela assume. Diante disso, se realiza o teste do Multiplicador de Lagrange $\left(M L_{p}\right)$ para analisar a defasagem espacial na variável dependente, com hipótese nula $p=0$ e Multiplicador de Lagrange $\left(M L_{\lambda}\right)$ para observar a defasagem no termo de erro, com hipótese nula $\lambda=0$. Em caso dos testes não serem significativos, o resultado do modelo é obtido através de MQO (BONDEZAN et al., 2018).

Nesse contexto, quando somente $M L_{p}$ for significativo, o modelo mais adequado é o de Defasagem Espacial (SAR):

$$
y=p W y+X \beta+\varepsilon
$$

(6)

Em que $W y$ é a variável dependente defasada pela matriz de pesos espaciais, $p$ é o coeficiente autoregressivo espacial, que mede a influência média dos vizinhos sobre a observação no vetor $y$ e que indica a proporção da variação total em $y$ explicada pela dependência espacial, $X$ é uma matriz de variáveis explicativas exógenas, $\beta$ são os coeficientes da regressão e $\epsilon$ distúrbio aleatório.

Contudo, quando somente $M L_{\lambda}$ for significativo, o modelo mais consistente é o de Erro Espacial (SEM):

$$
y=X \beta+\xi
$$

Em que $X$ é uma matriz de variáveis explicativas exógenas, $\beta$ são os coeficientes da regressão, $\xi=\lambda W \xi+\epsilon$, no qual o coeficiente $\lambda$ é o parâmetro do erro autorregressivo espacial que acompanha a defasagem, $W \xi$, mais o termo de erro, $\epsilon$.

Além disso, caso ambos sejam significativos, verifica-se as extensões do teste, ou seja, os Multiplicadores de Lagrange robusto, sendo eles: $M L_{p}^{*}$ e $M L_{\lambda}^{*}$. O Multiplicador de Lagrange mais significativo indica o modelo mais apropriado para ser estimado, de acordo com Bondezan et al. (2018). 


\section{RESULTADOS E DISCUSSÕES}

\subsection{Distribuição da violência no Estado de Pernambuco}

Inicialmente, exibe-se a distribuição espacial da população estimada das cidades pernambucanas para o ano de 2016 (Mapa 1), além das ocorrências de homicídios (Mapa 2) e roubos (Mapa 3). Essa análise permite verificar se as variáveis citadas se encontram distribuídas aleatoriamente ou seguem um padrão espacial sistemático no estado.

As áreas mais escuras dos mapas indicam os municípios que apresentam o maior número de habitantes, homicídios (CVLI) e roubos (CVP) no território pernambucano. A priori, observa-se que a distribuição espacial das variáveis de criminalidade no estado sugere a existência de clusters espaciais no Agreste, Sertão e Região Metropolitana do Recife (RMR).

Almeida (2012) orienta realizar um teste estatístico formal para confirmar se as variáveis estão distribuídas no espaço aleatoriamente ou autocorrelacionadas, através do Índice de Moran global. Os resultados são apresentados na seção seguinte.

Mapa 1 - Distribuição da população municipal estimada para 2016.

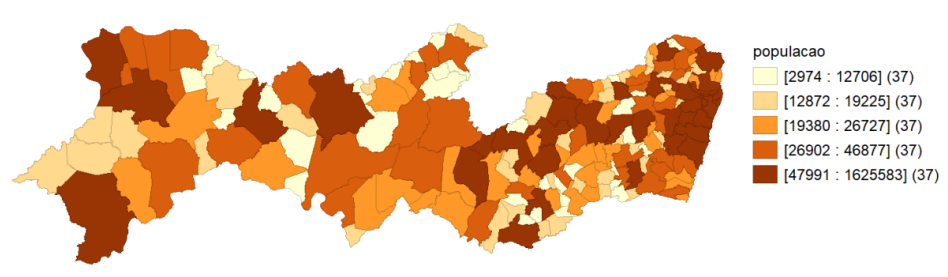

Fonte: Elaboração própria (2019) a partir do software GeoDa.

Mapa 2 - Distribuição do número de CVLI em 2016.

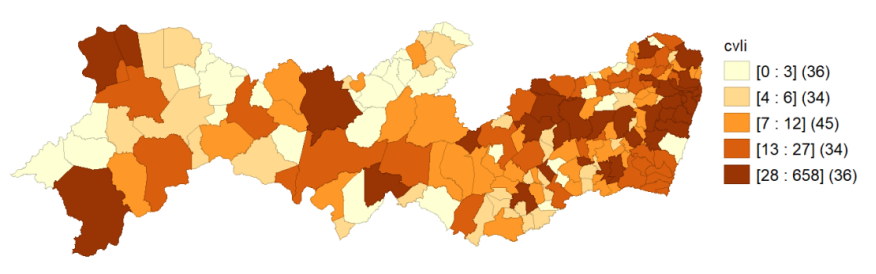

Fonte: Elaboração própria (2019) a partir do software GeoDa. 


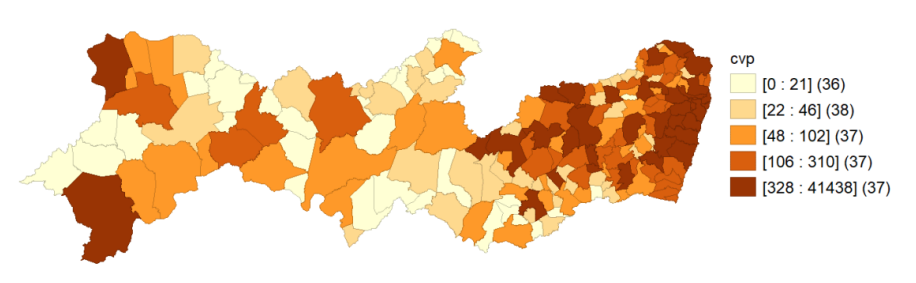

Fonte: Elaboração própria (2019) a partir do software GeoDa.

\subsection{Teste de autocorrelação global e local}

Essa seção apresenta a análise do teste de autocorrelação global e local para os casos de homicídio (CVLI) e roubo (CVP) no território pernambucano. Nesse sentido, a Tabela 1 exibe a primeira etapa da AEDE, que verifica se as variáveis de interesse estão distribuídas no espaço geográfico aleatoriamente ou autocorrelacionadas.

O $I$ de Moran tem um valor esperado $E[I]$ de $-1\left[\frac{1}{n-1}\right]$. Deste modo, tem-se que o $E[I]$ dos 185 municípios do Pernambuco é (-0.0055). Portanto, valores acima disso indicam a existência de autocorrelação espacial positiva. Assim, observa-se que os valores estimados do $I$ de Moran são superiores ao $E[I]$, indicando associação espacial positiva das ocorrências de homicídios e roubos no estado.

Além disso, constata-se que o $I$ de Moran global foi significativo a 1\% para ambas as convenções espaciais, no entanto, a matriz Rainha exibiu o maior coeficiente, sendo esta a escolhida para análise espacial no estudo. Ademais, conclui-se que os municípios que possuem alto (baixo) índice de criminalidade estão circundados por municípios que também exibem alto (baixo) índice de violência. Em outros termos, existe similaridade entre os valores de uma determinada localidade com a dos seus vizinhos, no que diz respeito as ocorrências de homicídios e roubos (ALMEIDA, 2012).

Tabela 1 - Estatísticas globais I de Moran para as variáveis dependentes.

\begin{tabular}{c|cccc}
\hline \multirow{2}{*}{ Variáveis } & Convenção & $I$ & p-valor & z-valor \\
\hline \multirow{2}{*}{ CVLI } & Rainha & 0.3212 & 0.001 & 6.6525 \\
\cline { 2 - 5 } & Torre & 0.2185 & 0.001 & 6.8421 \\
\hline \multirow{2}{*}{ CVP } & Rainha & 0.4959 & 0.001 & 10.4811 \\
\cline { 2 - 4 } & Torre & 0.4490 & 0.001 & 13.7070 \\
\hline
\end{tabular}

Fonte: Elaboração própria (2019) a partir do software GeoDa. 
Após a constatação de significância do $I$ de Moran global, buscou-se identificar padrões de associação linear espacial ao nível local, através do $I$ de Moran local. Assim, para cada observação é mensurado este indicador. Em seguida, foram obtidos $n$ resultados dessa estatística e seus respectivos níveis de significância. Os resultados são apresentados através do mapa de clusters LISA, que combina a informação do diagrama de dispersão do $I$ de Moran com a do mapa de significância das medidas do índice de associação local (BONDEZAN et al., 2018).

Mapa 4 - Clusters univariado do número de homicídios (CVLI) em 2016.

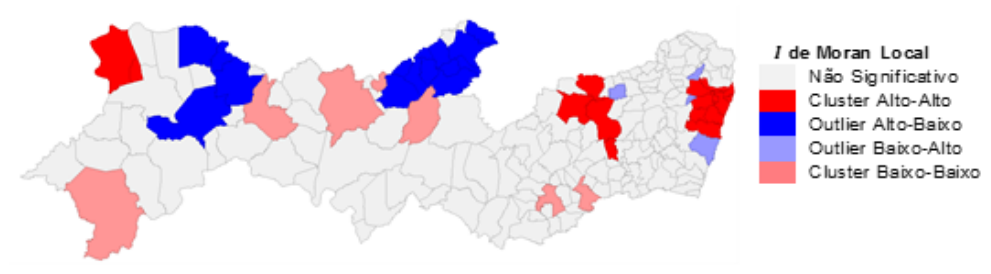

Fonte: Elaboração própria (2019) a partir do software GeoDa.

Mapa 5 - Clusters univariado do número de roubos (CVP) em 2016.

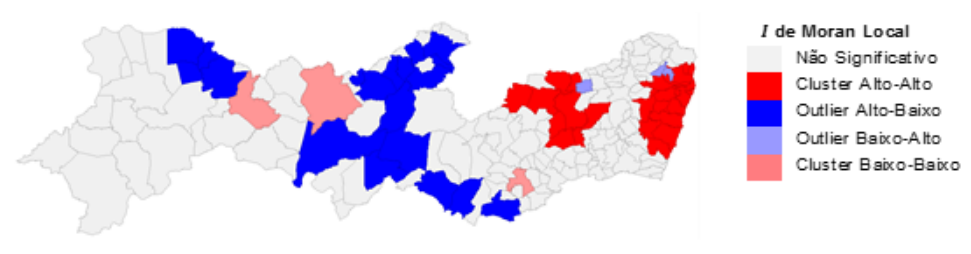

Fonte: Elaboração própria (2019) a partir do GeoDa.

Nesse contexto, os Mapas 4 e 5 exibem os clusters obtidos através do $I$ de Moran local para os casos de homicídio (CVLI) e roubo (CVP) no Pernambuco. Deste modo, os clusters apresentados nos mapas LISA são do tipo Alto-Alto (AA), Baixo-Baixo (BB), BaixoAlto (BA) e Alto-Baixo (AB).

O agrupamento AA corresponde aos municípios pernambucanos com altos índices de criminalidade (homicídios e roubos) com a média dos vizinhos que também exibem altos índices desse atributo. Por outro lado, BB refere-se as cidades com baixos índices de violência com a média dos vizinhos que também apresentam baixo índice desse atributo, e assim por diante.

É importante destacar que as ocorrências de homicídios e roubos se encontram concentradas na Região Metropolitana do Recife (RMR), Agreste e Sertão, como pode ser visualizado nos mapas. Além disso, observa-se que os municípios que possuem um elevado quantitativo populacional também concentram a criminalidade no estado (ver Mapa 1).

A maior parte do agrupamento Alto-Alto é composto pelos municípios da Região Metropolitana do Recife e do Agreste, no que tange as ocorrências de homicídios e roubos. Assim, se por um lado essas regiões apresentam elevada densidade populacional e desenvolvimento econômico, por outro também aglutinam problemas urbanos e socioeconômicos que favorecem o crescimento da violência no estado. 
O Sertão Pernambucano apresentou baixos índices de violência. Por essa razão, nessa mesorregião a maioria dos clusters são do tipo Baixo-Baixo ou Alto-Baixo, ou seja, existem algumas localidades com elevados índices de violência rodeadas por localidades com baixos índices de criminalidade. Esses clusters podem estar associados ao porte municipal e também a dinâmica econômica, política e social da localidade.

Por último, a Figura 1 apresenta os diagramas do $I$ de Moran global para CVLI (0.321) e CVP (0.496) obtidos com a matriz Rainha, que indicam dependência espacial da criminalidade no território pernambucano, como exposto anteriormente na Tabela 1.

Figura 1 - Diagrama de dispersão do $I$ de Moran para CVLI e CVP em 2016.
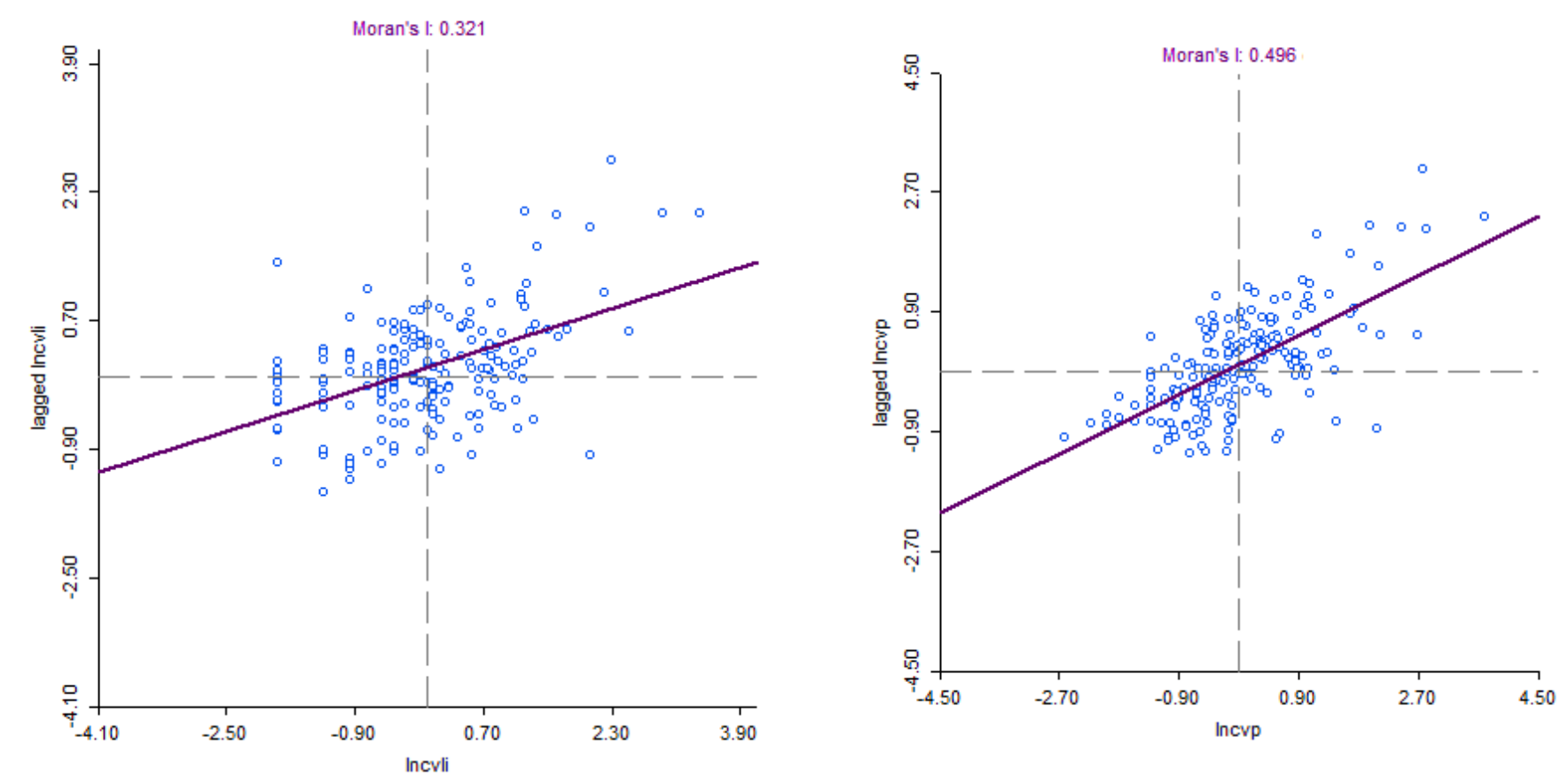

Fonte: Elaboração própria (2019) a partir do software GeoDa.

\subsection{Resultados dos modelos espaciais}

Essa seção exibe os resultados alcançados com os modelos econométricos com componentes espaciais. Os modelos foram estimados e adequados através das variáveis expostas no Quadro 1 para determinação e explicação da evolução das ocorrências de homicídios (CVLI) e roubos (CVP) no território pernambucano.

A Tabela 2 apresenta as estimações através de Mínimos Quadrados Ordinários (MQO) para as ocorrências de homicídios e roubos. As variáveis dos modelos estimados foram todas estatisticamente significativas ao nível de $1 \%, 5 \%$ e $10 \%$, com exceção da constante do modelo CVP. Além disso, as variáveis apresentam o sinal esperado e de acordo com o exposto no Quadro 2. Constata-se ainda o elevado poder de explicação dos modelos, uma vez que os $\mathrm{R}^{2}$ ajustados das estimações foram de $73,8 \%$ e $81,6 \%$, nesta ordem. 
Tabela 2 - Resultados estimados pelo método de MQO.

\begin{tabular}{|c|c|c|}
\hline Variáveis & CVLI & CVP \\
\hline Constante & $\begin{array}{c}-4.77679 * * * \\
(0.663686)\end{array}$ & $\begin{array}{l}-0.0466905 \\
(0.572455)\end{array}$ \\
\hline Densidade Demográfica & $\begin{array}{l}0.107339 * * \\
(0.0481473)\end{array}$ & $\begin{array}{c}0.500752 * * * \\
(0.054758)\end{array}$ \\
\hline Divórcio & $\begin{array}{l}0.118872 * * * \\
(0.0398748)\end{array}$ & $\begin{array}{l}0.110228 * * \\
(0.0522862)\end{array}$ \\
\hline Renda & $\begin{array}{c}0.497306 * * * \\
(0.0719848)\end{array}$ & $\begin{array}{l}0.103872 \\
(0.102449)\end{array}$ \\
\hline Atraso Escolar & $\begin{array}{c}0.732865 * * * \\
(0.155843)\end{array}$ & $\begin{array}{l}- \\
-\end{array}$ \\
\hline Educação & $\begin{array}{l}- \\
-\end{array}$ & $\begin{array}{c}-0.867567 * * * \\
(0.147054)\end{array}$ \\
\hline Tráfico de Drogas & $\begin{array}{l}0.123946 * * \\
(0.060599)\end{array}$ & $\begin{array}{c}0.227138 * * * \\
(0.07243)\end{array}$ \\
\hline Furtos & - & $\begin{array}{l}0.54654 * * * \\
(0.0962524)\end{array}$ \\
\hline Log Likelihood & -175.812 & -201.337 \\
\hline Critério de Akaike & 363.625 & 416.674 \\
\hline Critério de Schwarz & 382.947 & 439.216 \\
\hline $\mathrm{R}^{2}$ & 0.745865 & 0.822508 \\
\hline $\mathrm{R}^{2}$ Ajustado & 0.738766 & 0.816525 \\
\hline
\end{tabular}

Fonte: Elaboração própria (2019) a partir do software GeoDa. Nota: *** significância a 1\%, ** a $5 \%$ e * a $10 \%$; entre parênteses estão as estimativas de desviopadrão dos parâmetros.

A Tabela 3 apresenta o resultado dos testes de multicolinearidade, normalidade e heterocedasticidade para as regressões realizadas pelo método de MQO. Observa-se que os modelos estimados não apresentam normalidade na distribuição dos erros segundo o teste de Jarque-Bera. Os modelos estimados exibem leve multicolinearidade, uma vez que o Condition Number foi superior a 30 . Os testes de Breush-Pagan, Koenker-Bassett e White indicam que não há ausência de heterocedasticidade nas estimações. 
Tabela 3 - Diagnóstico da regressão estimado por MQO.

\begin{tabular}{ccc}
\hline Testes & CVLI & CVP \\
\hline Condition Number (Multicolinearidade) & 42.819735 & 46.778248 \\
\hline Jarque Bera (Normalidade) & 6.5730 & 174.1442 \\
Breush-Pagan (Heterocedasticidade) & $(0.03738)$ & $(0.00000)$ \\
\hline Koenker-Bassett (Heterocedasticidade) & 9.8874 & 19.6083 \\
& $(0.07849)$ & $(0.00325)$ \\
\hline White (Heterocedasticidade) & 9.4298 & $(0.3770$ \\
\hline
\end{tabular}

Fonte: Elaboração própria (2019) a partir do software GeoDa. Nota: a probabilidade (p-valor) dos testes encontram-se entre parênteses.

A Tabela 4 apresenta o diagnóstico da natureza da autocorrelação espacial para as variáveis de interesse da análise. O $I$ de Moran (Erro) tem como hipótese nula, a não existência de dependência espacial. Portanto, verifica-se que esse teste exibiu resultado estatisticamente significativo, indicando que os resíduos são autocorrelacionados no espaço para ambas as variáveis dependentes.

Os testes de $M L_{p}$ e $M L_{\lambda}$ sugerem a presença de dependência espacial para ambas as variáveis de interesse. Contudo, para CVLI o $M L_{\lambda}$ exibe valor superior ao $M L_{p}$, além disso, o teste robusto dos dois indicadores foram estatisticamente insignificantes. Em relação ao CVP, o $M L_{p}$ além de exibir um valor maior que $M L_{\lambda}$ seu teste robusto foi estatisticamente significativo, enquanto o outro foi insignificante. Portanto, o modelo mais indicado é com defasagem SAR.

Tabela 4 - Diagnóstico de autocorrelação espacial.

\begin{tabular}{ccc}
\hline Diagnóstico & CVLI & CVP \\
\hline$I$ de Moran (Erro) & $2.2516^{* *}$ & $4.4539^{* * *}$ \\
\hline$M L_{p}($ Defasagem $)$ & $2.7333^{*}$ & $39.8970^{* * *}$ \\
\hline$M L_{p}^{*}($ Defasagem) Robusto & 0.4177 & $24.6341^{* * *}$ \\
\hline$M L_{\lambda}($ Erro $)$ & $3.7108^{*}$ & $16.3718^{* * *}$ \\
\hline$M L_{\lambda}^{*}($ Erro $)$ Robusto & 1.3951 & 1.1089
\end{tabular}

Fonte: Elaboração própria (2019) a partir do software GeoDa. Nota: *** significância a 1\%,** a 5\% e * a 10\%.

A Tabela 5 apresenta os resultados das estimações com modelos de Erro Espacial (SEM) para as ocorrências de homicídios (CVLI) e Defasagem Espacial (SAR) para os casos de roubo (CVP) no território pernambucano.

A primeira estimação foi realizada com a especificação SEM-GMM de acordo com Kelejian e Prucha (1999), que utiliza o mecanismo (KP-HET) indicado por Kelejian e Prucha (2010) para lidar com o problema de heterocedasticidade desconhecida. A segunda estimação foi efetuada com Defasagem Espacial (SAR) através do estimador Spatial Heteroscedasticity and Autocorrelation Consistente 
Estimator (SHAC), que corresponde a uma alternativa para correção dos problemas de heterocedasticidade e autocorrelação espacial nos termos de erro, conforme Kelejian e Prucha (2007), Justo (2014) e Moreira e Fochezatto (2018).

O teste de Anselin-Kelejian $(0.275)^{2}$ não rejeitou a hipótese nula e, portanto, a autocorrelação nos resíduos da regressão foram ajustadas adequadamente, através da utilização do estimador robusto, oferecendo assim ao modelo com defasagem espacial interpretação e inferência robusta para os fatores determinantes dos casos de roubo no estado (MOREIRA e FOCHEZATTO, 2018).

As variáveis dependentes dos modelos econométricos com erro e defasagem espacial para as ocorrências de homicídios e roubos, respectivamente, exibem elevado nível de significância estatística, indicando efeitos de transbordamento e repercussão da criminalidade no território pernambucano.

Essa inferência implica que parte da violência observada nos municípios do estado são explicadas pelas altas taxas de criminalidade transferidas entre as localidades. Deste modo, cabe ao formulador de políticas públicas combater a criminalidade não somente ao nível local, mas também ao nível regional (PLASSA e PARRÉ, 2019).

Tabela 5 - Estimação dos modelos espaciais para CVLI e CVP.

\begin{tabular}{|c|c|c|}
\hline Variáveis & CVLI & CVP \\
\hline Constante & $\begin{array}{c}-4.5793259 * * * \\
(0.7325066)\end{array}$ & $\begin{array}{l}-0.6422596 \\
(0.6122805)\end{array}$ \\
\hline Densidade Demográfica & $\begin{array}{l}0.0931104 * \\
(0.0502104)\end{array}$ & $\begin{array}{c}0.2813698 * * * \\
(0.0874504)\end{array}$ \\
\hline Divórcio & $\begin{array}{c}0.1184519 * * * \\
(0.0449483)\end{array}$ & $\begin{array}{l}0.1179756^{* *} \\
(0.0534204)\end{array}$ \\
\hline Renda & $\begin{array}{c}0.4999990 * * * \\
(0.0750524)\end{array}$ & $\begin{array}{c}0.1077983 \\
(0.1036787)\end{array}$ \\
\hline Atraso Escolar & $\begin{array}{c}0.6735521 * * * \\
(0.1785169)\end{array}$ & - \\
\hline Educação & - & $\begin{array}{c}-0.7380453 * * * \\
(0.2003640)\end{array}$ \\
\hline Tráfico de Drogas & $\begin{array}{c}0.1295322 * * \\
(0.0572447)\end{array}$ & $\begin{array}{c}0.1950172 * * \\
(0.0793977)\end{array}$ \\
\hline Furtos & - & $\begin{array}{c}0.5227583 * * * \\
(0.1239043)\end{array}$ \\
\hline$p_{1}$ & - & $\begin{array}{c}0.3081481 * * * \\
(0.0938544)\end{array}$ \\
\hline$W_{1}$ & $\begin{array}{c}0.2127196^{* *} \\
(0.0886002)\end{array}$ & - \\
\hline Teste Anselin-Kelejian & & 0.275 \\
\hline Pseudo $\mathrm{R}^{2}$ & 0.7455 & 0.8608 \\
\hline Spatial Pseudo $\mathrm{R}^{2}$ Ajustado & & 0.8464 \\
\hline
\end{tabular}


Fonte: Elaboração própria (2019) a partir do software GeoDa. Nota: *** significância a 1\%, ** a 5\% e * a $10 \%$; entre parênteses estão as estimativas de desviopadrão dos parâmetros. Para estimação foi utilizado uma Kernel Triangular (Euclidean Distance).

Destaca-se ainda que as ocorrências de homicídios (CVLI) expressas através do modelo de Erro Espacial (SEM) retrata que a dependência ocorre devido a um fator exógeno, que conduz à heterogeneidade espacial (contágio aparente). Diante disso, a dependência espacial foi verificada através dos termos de erro, uma vez que apresentam-se autocorrelacionados no território estadual (DALBERTO, 2016).

No modelo estimado com variável dependente CVLI, os coeficientes das variáveis explicativas exibiram resultados estatisticamente significativos a 1\%,5\% e 10\%, indicando que as variáveis são determinantes das ocorrências de homicídios no Estado de Pernambuco. Além disso, o poder de explicação desses condicionantes foi de $74,5 \%$, enquanto que a defasagem do termo de erro foi estatisticamente significativa ao nível de $5 \%$, com valor de 0,21 .

Em relação ao modelo com a variável dependente CVP, apenas a constante e o nível de renda não exibiram significância estatística, contudo, as demais apresentaram elevada significância. O poder de explicação das variáveis foi de 84,6\%, com a variável de defasagem expressando significância a $1 \%$ e valor de 0,30 .

A respeito dos determinantes da criminalidade, verificou-se que densidade exibiu sinal positivo, indicando que a concentração populacional mantém relação direta com as ocorrências de homicídios e roubos no território pernambucano. Nessa perspectiva, o divórcio também apresentou associação direta com o aumento da violência no estado (OLIVEIRA, 2008; CERQUEIRA e LOBÃO, 2004; SHAW e MCKAY, 1942).

O nível de renda configura um cenário de grandes oportunidades para atividade ilegal por determinados agentes. Assim, localidades com elevado progresso econômico, além de concentrarem uma enorme população também possuem um ambiente ideal para o crescimento da violência. Portanto, uma elevação da renda amplia as ocorrências de homicídios no estado, enquanto que os casos de roubo são determinados por outros fatores mais relevantes no território estadual, à exemplo tem-se o tráfico de drogas e os furtos que são altamente significativos (MOREIRA e FOCHEZATTO, 2018).

O atraso escolar exibiu relação direta com o aumento do número de homicídios, uma vez que a distorção idade-série dos indivíduos no ambiente escolar aumenta a probabilidade de o agente migrar para a atividade ilegal, afetando o nível de bem-estar social da localidade. Por outro lado, a escolaridade apresentou relação inversa com os casos de roubo, indicando a existência de um alto custo de oportunidade para os indivíduos que possuem elevado grau de instrução adentrarem no mercado ilegal, assim a acumulação de capital humano tende a reduzir a criminalidade ao longo do tempo (OLIVEIRA, 2008; TEIXEIRA, 2011; BECKER, 1968).

Em relação ao tráfico de drogas, observa-se que essa atividade ilegal apresenta associação com os casos de homicídio no estado, uma vez que os conflitos territoriais entre os traficantes aumentam a probabilidade de assassinato no estado. Ademais, tráfico de drogas e furtos exibem relação direta com as ocorrências de roubos, em razão dessa atividade ser essencial para a manutenção dos usuários de drogas deste mercado ilegal (FAJNZYLBER e ARAÚJO JÚNIOR, 2001; MARIANO, 2010; ROCHA, 2012). 


\section{CONSIDERAÇÕES FINAIS}

Este estudo teve como finalidade contribuir com a identificação dos fatores capazes de explicar a evolução da criminalidade no território pernambucano em 2016, assim como fornecer informações para os formuladores de políticas públicas do estado no que concerne ao combate da violência, que tanto afeta a economia e o bem-estar da população, sobretudo nos grandes centros urbanos.

O trabalho detectou que elevados níveis de criminalidade e insegurança em uma localidade do Pernambuco influenciam o nível de violência dos seus vizinhos. Nesse sentido, constatou-se que o combate à violência no território estadual deve ocorrer de forma integrada entre as regiões para que os resultados possam ser maximizados.

É importante destacar que as variáveis econômicas, sociais e geográficas são relevantes na determinação dos índices de criminalidade no Estado de Pernambuco. Nesse contexto, os casos de homicídio tem como condicionantes densidade, divórcio, atraso escolar, nível de renda e tráfico de drogas, ao mesmo tempo em que ocorrências de roubos tem densidade, divórcio, escolaridade, tráfico de drogas e furtos como determinantes.

Os resultados indicaram que existe um efeito de transbordamento dos casos de roubo entre as localidades, isto é, a violência de um município afeta a do seu vizinho. Em relação as ocorrências de homicídios, o efeito espacial foi heterogêneo, ou seja, não ocorre apenas em uma localidade, além disso, repercute sobre os diversos locais do Pernambuco, com intensidade diferente a depender da força do efeito. Neste caso, existe efeito de transbordamento e repercussão da criminalidade no estado.

Por fim, conclui-se que a criminalidade no território pernambucano se encontra concentrada na Região Metropolitana do Recife (RMR), Agreste e Sertão, como indicado na análise espacial, através do levantamento de clusters.

\section{REFERÊNCIAS}

ALMEIDA, E. Econometria Espacial Aplicada. Alínea: Campinas-SP, 2012.

ANSELIN, L. Spatial econometrics. A companion to theoretical econometrics, v. 310330, 1999.

Local indicators of spatial association -LISA. Geographical analysis, v. 27, n. 2, p. 93-115, 1995.

ARAUJO JUNIOR, A.; FAJNZYLBER, P. Crime e economia: um estudo das microrregiões mineiras. Revista Econômica do Nordeste, Fortaleza, v. 31, n. esp., p. 630-659, nov. 2000.

BECKER, G. Crime and punishment: an economic approach. Journal of Political Economy, v.76, p. 169-217, 1968.

BLOCK, Michael K.; HEINEKE, John M. A labor theoretic analysis of the criminal choice. The American Economic Review, v. 65, n. 3, p. 314-325, 1975.

BONDEZAN, K. L.; LUCAS, M. S.; CUNHA, M. S. Determinantes socioeconômicos da criminalidade no estado do Paraná: uma análise espacial. Anais do XXII Encontro de Economia da Região Sul, 2018. Disponível: http://twixar.me/GHV1. Acesso em: 17 set. 2019.

CARRETS, Fernanda Dachi; DE OLIVEIRA, Jonatas; MENEZES, Gabrielito Rauter. A criminalidade no Rio Grande do Sul: uma análise espacial para anos de 2005, 2010 e 2015. Perspectiva Econômica, v. 14, n. 1, p. 33-46, 2018.

CERQUEIRA, D. (Coord). Atlas da Violência 2018. Rio de Janeiro: Ipea/FBSP. Disponível em: < http://twixar.me/4CV1>. Acesso em: 17 set. 2019. 
CERQUEIRA, D.; LOBÃO, W. Determinantes da Criminalidade: Arcabouços Teóricos e Resultados Empíricos. Dados - Revista de

Ciências Sociais. Rio de Janeiro, vol.47, n.2, 2004. p.233 - 269.

DALBERTO, Cassiano Ricardo. A pobreza extrema e a diversificação econômica dos municípios de Minas Gerais: uma análise espacial. XVII Seminário da Economia Mineira, CEDEPLAR/UFMG. Anais. Diamantina, Minas Gerais, 2016. Vol. 01. P. 121-143.Disponível em: https://diamantina.cedeplar.ufmg.br/2016/anais_economia.html Acesso em 03/11/2019.

EHRLICH, I. Participation in Illegitimate Activities: A Theoretical and Empirical Investigation. Journal of Political Economy, v.81, n.3, p.521-565, may.-jun., 1973.

FAJNZYLBER, P.; ARAUJO, JR. Violência e Criminalidade. In: Menezes-Filho, N.; Lisboa, M. (Org.). Microeconomia e Sociedade no Brasil. Rio de Janeiro: EPGE-FGV, 2001.

GLAESER, E. L.; SACERDOTE, B. Why is there more crime in cities? Journal of political economy, v. 107, n. S6, p. S225-S258, 1999.

INSTITUTO DE PESQUISA ECONÔMICA APLICADA - Ipeadata. Dados macroeconômicos e regionais. Disponível em: http://www.ipeadata.gov.br/Default.asp $\underline{x}$ Acesso em 6 nov. 2019.

JUSTO, W. R. Crescimento Econômico dos Municípios Baianos de 2000 a 2010 à luz da Nova Geografia Econômica e da Econometria Espacial. In: Encontro Pernambucano de Economia Política para o Desenvolvimento Estadual, 3., 2014, Recife. Anais... Recife, 2014.

LEUNG, Siu Fai. Dynamic deterrence theory. Economica, p. 65-87, 1995.

LOBO, L. F.; CARRERA-FERNADEZ, J. A Criminalidade na Região Metropolitana de Salvador. In: Anais XXXI Encontro Nacional de Economia, Porto Seguro, 2003.

KELEJIAN, H. H.; PRUCHA, I. R. A. Specification and Estimation of Spatial Autoregressive Models with Autoregressive and Heteroskedastic Disturbances. Journal of Econometrics, Amsterdam, v. 157, n. 1, p. 53-67, 2010.

A Generalized Moments Estimator for the Autoregressive Parameter in a Spatial Model. International Economic Review, v. 40, p. 509-533, 1999.

.HAC Estimation in a Spatial Framework. Journal of Econometrics, Amsterdam, v. 140, n. 1,

p. 131-154, 2007.

MARIANO, Rodrigo Silva et al. Fatores socioeconômicos da criminalidade no Estado de São Paulo: um enfoque da economia do crime. São Paulo, PUC-SP. (Dissertação de Mestrado), 2010.

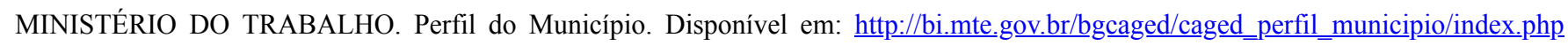
Acesso em: 6 nov. 2019.

MOREIRA, Romilson do Carmo; FOCHEZATTO, Adelar. Análise espacial da criminalidade no estado da Bahia. RDE-Revista de Desenvolvimento Econômico, v. 3, n. 38, 2018.

OLINI, Rafael Médici et al. Homicídio e desigualdade de renda: uma análise espacial para o estado de Mato Grosso em 2000 e 2010. Economic Analysis of Law Review, v. 9, n. 3, p. 107-130, 2019.

OLIVEIRA JÚNIOR, Fernando José Moreira de et al. Trinta anos de homicídios em Pernambuco: tendência e distribuição espacial no período de 1981 a 2010. Tese de Doutorado. Centro de Pesquisas Aggeu Magalhães, 2013.

OLIVEIRA, C. A. Análise Espacial da Criminalidade no Rio Grande do Sul. Revista de Economia (Curitiba), v. 34, p. 35-60, 2008. 
PLASSA, Wander; PARRÉ, José Luiz. A violência no estado do Paraná: uma análise espacial das taxas de homicídios e de fatores socioeconômicos. Economia e Desenvolvimento, v.31, e1, p. 01 - 16, 2019.

PLASSA, Wander; PASCHOALINO, Pietro André Telatin; SANTOS, M. P. Determinantes socioeconômicos das taxas de homicídios no nordeste brasileiro: uma análise espacial. Anais do XIII Encontro de Economia Baiana, 2017.

RATTON, José Luiz; GALVÃO, Clarissa; FERNANDEZ, Michelle. O pacto pela vida e a redução de homicídios em Pernambuco. Tornando as cidades brasileiras mais seguras: edição especial dos diálogos de segurança cidadã. Instituto Igarapé: Rio de Janeiro, 2014.

ROCHA, Andréa Pires. Trajetórias de adolescentes apreendidos como mulas do transporte de drogas na região da fronteira (Paraná) Brasil-Paraguai: exploração de força de trabalho e criminalização da pobreza. Franca, 2012.

SANTOS, Bruno Freitas Alves dos. Economia do crime: especificidades no caso brasileiro. Florianópolis, 2007.

SANTOS, L.; RAIA JUNIOR, A. Análise espacial de dados geográficos: a utilização da Exploratory Spatial Data Analysis-ESDA para identificação de áreas críticas de acidentes de trânsito no município de São Carlos (SP). Sociedade \& Natureza, v. 18, n. 35, 2006.

SECRETARIA DE DEFESA SOCIAL DO ESTADO DE PERNAMBUCO. Indicadores criminais em Pernambuco. Disponível em: http://www.sds.pe.gov.br/estatisticas. Acesso em 6 nov. 2019.

SHAW, C. R.; MCKAY, H. D. Juvenile delinquency and urban areas. Chicago: IIl, 1942.

TEIXEIRA, E. C. Dois ensaios acerca da relação entre criminalidade e educação - Tese apresentada para a obtenção do título de Doutor em Ciências- Área de concentração: Economia aplicada - Ano de obtenção: 2011.

UCHÔA, Carlos Frederico; MENEZES, Tatiana Almeida. Spillover espacial da criminalidade: Uma aplicação de Painel Espacial para os Estados Brasileiros. XL Encontro Nacional de Centro de Pós-Graduação em Economia, Porto de Galinhas, v. 11, 2012.

ZHANG, J. The effect of welfare programs on criminal behavior: A theoretical and empirical analysis. Economic Inquiry, v. 35, n. 1, p. $120-137,1997$.

\section{Notas de Rodapé}

1. O teste de Anselin-Kelejian testa a hipótese nula de que não há autocorrelação nos resíduos do modelo. 